\title{
Stem cells and the aging hematopoietic system
}

\author{
Isabel Beerman ${ }^{1}$, William J Maloney ${ }^{2}$, Irving L Weissmann ${ }^{3}$, and Derrick J Rossi ${ }^{1}$ \\ ${ }^{1}$ Department of Pathology, Harvard Medical School, Harvard Stem Cell Institute, Immune Disease \\ Institute, Program in Cellular and Molecular Medicine, Children's Hospital Boston, 200 Longwood \\ Ave, Warren Alpert Building, Room \#253, Boston, MA 02115, United States \\ 2Orthopaedic Research Laboratories, Department of Orthopaedic Surgery, Stanford University \\ School of Medicine, 300 Pasteur Drive, R105, Stanford, CA 94305, United States \\ ${ }^{3}$ Stanford Institute for Stem Cell Biology and Regenerative Medicine, Stanford University Cancer \\ Center, and Department of Pathology, Stanford University School of Medicine, Stanford, CA \\ 94305, United States
}

\begin{abstract}
Advancing age is accompanied by a number of clinically significant conditions arising in the hematopoietic system that include: diminution and decreased competence of the adaptive immune system, elevated incidence of certain autoimmune diseases, increased hematological malignancies, and elevated incidence of age-associated anemia. As with most tissues, the aged hematopoietic system also exhibits a reduced capacity to regenerate and return to normal homeostasis after injury or stress. Evidence suggests age-dependent functional alterations within the hematopoietic stem cell compartment significantly contribute to many of these pathophysiologies. Recent developments have shed light on how aging of the hematopoietic stem cell compartment contributes to hematopoietic decline through diverse mechanisms.
\end{abstract}

\section{Introduction}

Aging within tissue-specific stem cell compartments is believed to play a central role in the pathophysiology of aging in many tissues through a declining capacity to mediate normal homeostatic tissue maintenance and regenerative response [ $\left.1^{\circ}\right]$. Hematopoietic stem cells (HSCs) mediate ongoing blood cell generation over the lifetime of the organism through their sustained ability to self-renew to preserve the stem cell pool, and to differentiate to give rise to all terminally differentiated blood cells. Owing to the short lifespan of many effector cells, blood cell production is an ongoing process with estimates suggesting the production of $10^{11}$ blood cells in adult humans daily. Despite the enormous proliferative and regenerative capacity of the hematopoietic system [2] aging is nonetheless accompanied by an overall reduction in hematopoietic competence [3].

Age-associated decline has been best characterized in the adaptive immune system and is driven, partly, by thymic involution, reduced T-cell production and function, and clonal 
expansion of memory T-cells [4,5]. B-cell production and function is similarly attenuated, and as with T-cells, the B-cell pool is predominated by antigen-experienced memory cells in the elderly [6-8]. Compounding the deficiencies in adaptive and humoral response, diminished competence and integrity of epithelial barriers in the skin, lung, and gut leads to an increased pathogenic challenge to the innate immune system with age. As a result, activation of innate responses and elevated plasma levels of cytokines including IL-6, IL-1 $\beta$, and TNFa can lead to a chronic, subclinical inflammatory state that is believed to contribute to the emergence and progression of a variety of age-related diseases [6,9].

The mechanisms underlying aging of the hematopoietic system are varied, and include intrinsic and extrinsic factors associated with the aging environment that combine to adversely influence hematopoietic effector cell production and function. However, increasing evidence suggests that age-dependent cellular and molecular alterations within the most primitive hematopoietic stem cell compartment may also contribute significantly to hematopoietic decline during aging.

\section{Hematopoietic stem cell aging: numbers and function}

A decline in the functional potential of HSCs with age is well documented in murine models [10-13]. Purified HSCs from young or old mice competitively transplanted against young whole bone marrow (WBM) cells have revealed that HSCs from old mice have a diminished overall reconstitution potential that may be primarily driven by age-associated DNA damage accumulation [14-18]. Murine HSCs also exhibit cell autonomous changes in lineage potential during aging showing attenuated lymphoid lineage output, whereas myeloid lineage potential is maintained or even increased (Figure 1) [10-13,19-21]. Consistent with this functional read-out, expression profiling of purified HSCs from young and old mice revealed that aged HSCs have decreased expression of gene programs associated with lymphoid specification and function, whereas genes involved in myeloid specification and function were upregulated [11]. These data suggest that molecular differences in the priming of lineage specification programs underlie the age-associated change in HSC lineage potential [11].

As with most tissues, aging in the hematopoietic system is associated with increased frequency of malignant transformation including elevated incidence of chronic and acute leukemias [22]. The fact that pediatric leukemias tend to involve lymphoid lineages [23], while myeloid leukemias become dominant in the older population [24] raises the possibility that age-associated changes in lineage potential of HSCs might directly influence the spectrum of diseases associated with hematopoietic aging [11]. In support of this, Dorshkind and colleagues recently evaluated the influence of age on disease outcome in an overexpression system utilizing BCR-ABL, the fusion gene associated with chronic myelogenous leukemia (CML) [24]. Enforced expression of BCR-ABL in the marrow of young mice led to both myeloproliferative disease (MPD) and B-cell leukemia upon transplantation, whereas transplantation of bone marrow from old mice expressing the fusion protein predominantly gave rise to MPD with rare lymphoid involvement [24]. This study provided compelling evidence that the age of the stem/progenitor cell compartment can exert profound influence on the spectrum of diseases arising during aging. Intriguingly, HSCs 
aging is accompanied by elevated expression of genes involved in the development of myeloid leukemia such as $\mathrm{Aml}, \mathrm{Pml}$, and Eto suggesting that upregulation of such protooncogenes may be another mechanism predisposing the elderly to myelogenous disease development [11].

Counter-intuitively, the loss of functional activity of stem cells from old mice is concomitant with substantial elevation in the frequency of phenotypically defined HSCs in the bone marrow of common strains of laboratory mice [11-13,25]. This expansion of the HSC pool with age is not dictated by the age of the bone marrow microenvironment; HSCs from old mice maintain an increased expansion potential compared to young HSCs even upon transplantation into young recipients $[11,26]$. These results raise the possibility that a feedback mechanism regulating stem cell numbers may operate to compensate for the percell loss in HSC function during aging by leading to an increase in the size of the stem cell pool.

Much less is known about the maintenance of the primitive stem cell pool during aging in humans. Current dogma holds that declining marrow frequencies of hematopoietic stem cells accompany aging and in such a way contribute to the decline of the human hematopoietic system with advancing age. This postulate has been supported by the observation of reduced cellularity in the bone marrow of the elderly [3], and by analysis of CD34+ bone marrow cells that showed a decrease in numbers with age in one study [27]. However, since CD34+ bone marrow cells are extremely heterogeneous, we sought to quantify the bone marrow frequency of human HSCs during aging more precisely [28-32]. To this end, we isolated mononuclear cells from the bone marrow of 19 consented, healthy individuals of different ages and stained them with a panel of 12 antibodies to identify and quantify HSCs (Figure 2a). Strikingly, and in contrast to the previously reported age-dependent decrease of CD34 ${ }^{+}$ $\mathrm{BM}$ cells, we observed a significant age-associated increase in frequency of lineage ${ }^{-} \mathrm{CD} 34^{+}$ CD $38^{-} \mathrm{CD} 90^{+}$cells (Figure $2 \mathrm{~b}$ ), a surface phenotype most rigorously used to define HSCs [28]. Consistent with these results, Taraldsrud et al. recently reported a significant ageassociated increase in $\mathrm{CD} 34^{+} \mathrm{CD} 38^{-}$bone marrow frequency $\left[33^{\circ}\right]$. Thus, counter to the prevailing view that hematopoietic stem cell frequency diminishes during aging, these results suggest that the frequency of primitive human HSCs in bone marrow increases with advancing age. It remains to be addressed, however, whether a per-cell loss in stem cell activity, similar to that which has been reported in mice, also accompanies human HSC aging.

\section{Hematopoietic stem cell subtypes: influence on aging}

Transplantation studies evaluating whole bone marrow in limiting dilution [19,34], or using purified stem cell populations $\left[35,36^{\circ *}, 37^{\circ}\right]$ have revealed the existence of functionally distinct HSC clonal subtypes that reconstitute irradiated recipients with distinct lineagebiases. The fact that the defined lineage potentials of these clonal subtypes can be maintained through successive recipients indicates that the epigenetic marks underwriting the functional differences between distinct HSC subtypes are relatively stable $\left[19,34,35,36^{\circ}\right.$, $37^{\circ}$ ]. The recent demonstration that such lineage biased HSCs can be prospectively isolated and purified based on differential expression of Slamf1 (CD150) $\left[36^{\circ *}, 38^{\circ *}\right]$ or by differences 
in dye efflux activity [37"* ] has opened the possibility of evaluating different HSC clonal subtypes at the molecular level. Such analysis has revealed that the functional potential associated with distinct clonal subtypes is underwritten by differences in lineage priming $\left[36^{\circ}\right]$, and that they are differently regulated by TGF- $\beta$ signaling $\left[37^{\circ *}\right]$.

The ability to identify HSC subtypes has also provided an opportunity to evaluate changes in the clonal composition of the stem cell pool during aging. Such analysis has revealed that HSCs clones primed toward myeloid differentiation progressively predominate the stem cell pool with advancing age $\left[36^{\circ}\right]$. The mechanism propelling the age-associated predominance of myeloid-biased clones with age was proposed to be a more robust self-renewal potential compared to the lymphoid-biased stem cell subtype [36*0], possibly combined with differential response to the aged cytokine milieu $\left[37^{\circ}\right]$. Collectively, these studies provide evidence that selective expansion of myeloid-biased HSC clones with age underlies the change in stem cell lineage potential from lymphopoiesis to myelopoiesis associated with aging. These studies also raise the possibility that age-dependent changes in clonal composition of the stem cell compartment might ultimately be important for dictating the types of hematopoietic malignancies manifested at young or old ages. It remains to be determined if the human HSC compartment is also composed of clones with distinct functional potentials, and if so, how aging impacts the clonal composition of the stem cell pool.

\section{Myelodysplastic syndrome and epigenetic dysregulation of stem cells}

The progression from HSCs to differentiated progeny involves coordinated control of sequential gene expression programs leading to activation or repression of lineage-specific genes, which has been shown to be under epigenetic control [39-42]. As changes in lineage potential are central to the aging of the stem cell compartment, it is perhaps not surprising that age-dependent changes to the epigenome and/or epigenetic dysregulation have been linked to the functional decline of HSCs $\left[1^{\circ}\right]$. In humans, the most compelling evidence for epigenetic involvement in HSC aging is the elevated incidence of myelodysplastic syndrome (MDS) in the elderly. Encompassing a spectrum of related diseases, MDS is a clonal stem cell disorder affecting multiple blood lineages that results from both genetic and epigenetic deregulation [43]. Aberrant DNA methylation patterns are thought to play an important role in the emergence of MDS, and methyl-silencing of a number of genes is prognostic for progression of the disease [44,45]. For example, the tumor suppressor $p 15^{I N K 4 B}$ is inactivated by DNA methyl-silencing in a significant percent of MDS patients, with $70 \%$ of these patients going on to develop acute myeloid leukemia (AML) [46]. The mechanistic importance of gene silencing by DNA methylation in the pathophysiology of MDS has been confirmed in clinical trials using two potent inhibitors of cytosine methylation, 5Azacytidine and 5-Aza-2'-deoxycytidine (decitabine) [47-49]. Although the precise mode of action of these demethylating agents in MDS remains unclear, it appears to involve epigenetic reprogramming and re-establishment of normal stem cell function by derepressing genes silenced by DNA hypermethylation [50]. 


\section{Conclusions}

Aging of many tissues and organs is invariably accompanied by a reduced capacity to adequately maintain normal tissue homeostasis, or regenerate after injury. Consistent with this, many age-related conditions observed in the elderly suggest an imbalance between cell loss and cell renewal. The hematopoietic system is no exception, exhibiting homeostatic imbalance in the production of multiple effecter cells, and a predisposition to certain hematological diseases during aging. As discussed herein, studies have pointed toward intrinsic deficits in HSC function, and epigenetic dysregulation as important contributing factors behind hematopoietic decline and malignancy during aging (Figure 3).

\section{Acknowledgments}

We would like to sincerely thank Brian Garrison, Roi Gazit, and Wataru Ebina for supportive discussions and effort.

\section{References and recommended reading}

Papers of particular interest, published within the annual period of review, have been highlighted as:

- of special interest

•• of outstanding interest

1•. Rossi DJ, Jamieson CH, Weissman IL. Stems cells and the pathways to aging and cancer. Cell. 2008; 132:681-696. A comprehensive review discussing aging in various adult stem cell compartments, and the connection between stem cell aging and cancer development. [PubMed: 18295583]

2. Harrison DE. Mouse erythropoietic stem cell lines function normally 100 months: loss related to number of transplantations. Mech Ageing Dev. 1979; 9:427-433. [PubMed: 37377]

3. Ogawa T, Kitagawa M, Hirokawa K. Age-related changes of human bone marrow: a histometric estimation of proliferative cells, apoptotic cells, T cells, B cells and macrophages. Mech Ageing Dev. 2000; 117:57-68. [PubMed: 10958923]

4. Pawelec G, Hirokawa K, Fulop T. Altered T cell signalling in ageing. Mech Ageing Dev. 2001; 122:1613-1637. [PubMed: 11511400]

5. Goronzy JJ, Lee WW, Weyand CM. Aging and T-cell diversity. Exp Gerontol. 2007; 42:400-406. [PubMed: 17218073]

6. Franceschi C, Bonafe M, Valensin S, Olivieri F, De Luca M, Ottaviani E, De Benedictis G. Inflammaging. An evolutionary perspective on immunosenescence. Ann N Y Acad Sci. 2000; 908:244-254. [PubMed: 10911963]

7. Dorshkind K, Swain S. Age-associated declines in immune system development and function: causes, consequences, and reversal. Curr Opin Immunol. 2009; 21:404-407. [PubMed: 19632102]

8. Linton PJ, Dorshkind K. Age-related changes in lymphocyte development and function. Nat Immunol. 2004; 5:133-139. [PubMed: 14749784]

9. Tsaknaridis L, Spencer L, Culbertson N, Hicks K, LaTocha D, Chou YK, Whitham RH, Bakke A, Jones RE, Offner H, et al. Functional assay for human CD4+CD25+ Treg cells reveals an agedependent loss of suppressive activity. J Neurosci Res. 2003; 74:296-308. [PubMed: 14515359]

10. Kim M, Moon HB, Spangrude GJ. Major age-related changes of mouse hematopoietic stem/ progenitor cells. Ann N Y Acad Sci. 2003; 996:195-208. [PubMed: 12799297]

11. Rossi DJ, Bryder D, Zahn JM, Ahlenius H, Sonu R, Wagers AJ, Weissman IL. Cell intrinsic alterations underlie hematopoietic stem cell aging. Proc Natl Acad Sci USA. 2005; 102:91949199. [PubMed: 15967997] 
12. Morrison SJ, Wandycz AM, Akashi K, Globerson A, Weissman IL. The aging of hematopoietic stem cells. Nat Med. 1996; 2:1011-1016. [PubMed: 8782459]

13. Sudo K, Ema H, Morita Y, Nakauchi H. Age-associated characteristics of murine hematopoietic stem cells. J Exp Med. 2000; 192:1273-1280. [PubMed: 11067876]

14. Rossi DJ, Bryder D, Seita J, Nussenzweig A, Hoeijmakers J, Weissman IL. Deficiencies in DNA damage repair limit the function of haematopoietic stem cells with age. Nature. 2007; 447:725729. [PubMed: 17554309]

15. Park Y, Gerson SL. DNA repair defects in stem cell function and aging. Annu Rev Med. 2005; 56:495-508. [PubMed: 15660524]

16. Nijnik A, Woodbine L, Marchetti C, Dawson S, Lambe T, Liu C, Rodrigues NP, Crockford TL, Cabuy E, Vindigni A, et al. DNA repair is limiting for haematopoietic stem cells during ageing. Nature. 2007; 447:686-690. [PubMed: 17554302]

17. Navarro S, Meza NW, Quintana-Bustamante O, Casado JA, Jacome A, McAllister K, Puerto S, Surralles J, Segovia JC, Bueren JA. Hematopoietic dysfunction in a mouse model for Fanconi anemia group D1. Mol Ther. 2006; 14:525-535. [PubMed: 16859999]

18. Reese JS, Liu L, Gerson SL. Repopulating defect of mismatch repair-deficient hematopoietic stem cells. Blood. 2003; 102:1626-1633. [PubMed: 12730104]

19. Cho RH, Sieburg HB, Muller-Sieburg CE. A new mechanism for the aging of hematopoietic stem cells: aging changes the clonal composition of the stem cell compartment but not individual stem cells. Blood. 2008; 111:5553-5561. [PubMed: 18413859]

20. Guerrettaz LM, Johnson SA, Cambier JC. Acquired hematopoietic stem cell defects determine Bcell repertoire changes associated with aging. Proc Natl Acad Sci USA. 2008; 105:11898-11902. [PubMed: 18697924]

21. Liang Y, Van Zant G, Szilvassy SJ. Effects of aging on the homing and engraftment of murine hematopoietic stem and progenitor cells. Blood. 2005; 106:1479-1487. [PubMed: 15827136]

22. Edwards BK, Howe HL, Ries LA, Thun MJ, Rosenberg HM, Yancik R, Wingo PA, Jemal A, Feigal EG. Annual report to the nation on the status of cancer, 1973-1999, featuring implications of age and aging on U.S. cancer burden. Cancer. 2002; 94:2766-2792. [PubMed: 12173348]

23. United States Cancer Statistics, 1999-2005. Incidence Results on World Wide Web URL: http:// wonder.cdc.gov/cancer-v2005.HTML

24. Signer RA, Montecino-Rodriguez E, Witte ON, McLaughlin J, Dorshkind K. Age-related defects in B lymphopoiesis underlie the myeloid dominance of adult leukemia. Blood. 2007; 110:18311839. [PubMed: 17554060]

25. de Haan G, Nijhof W, Van Zant G. Mouse strain-dependent changes in frequency and proliferation of hematopoietic stem cells during aging: correlation between lifespan and cycling activity. Blood. 1997; 89:1543-1550. [PubMed: 9057635]

26. Pearce DJ, Anjos-Afonso F, Ridler CM, Eddaoudi A, Bonnet D. Age-dependent increase in side population distribution within hematopoiesis: implications for our understanding of the mechanism of aging. Stem Cells. 2007; 25:828-835. [PubMed: 17158238]

27. Waterstrat, A., Oakley, E., Miller, A., Swiderski, C., Liang, Y., Van Zant, G. Mechanisms of stem cell ageing. In: Rudolph, KL., editor. Telomeres and Telomerase in Ageing, Disease, and Cancer. Springer; 2008. p. 111-140.

28. Majeti R, Park CY, Weissman IL. Identification of a hierarchy of multipotent hematopoietic progenitors in human cord blood. Cell Stem Cell. 2007; 1:635-645. [PubMed: 18371405]

29. Ishikawa F, Yasukawa M, Lyons B, Yoshida S, Miyamoto T, Yoshimoto G, Watanabe T, Akashi K, Shultz LD, Harada M. Development of functional human blood and immune systems in NOD/ SCID/IL2 receptor \{gamma\} chain(null) mice. Blood. 2005; 106:1565-1573. [PubMed: 15920010]

30. Michallet M, Philip T, Philip I, Godinot H, Sebban C, Salles G, Thiebaut A, Biron P, Lopez F, Mazars P, et al. Transplantation with selected autologous peripheral blood CD34+Thy1+ hematopoietic stem cells (HSCs) in multiple myeloma: impact of HSC dose on engraftment, safety, and immune reconstitution. Exp Hematol. 2000; 28:858-870. [PubMed: 10907648]

31. Negrin RS, Atkinson K, Leemhuis T, Hanania E, Juttner C, Tierney K, Hu WW, Johnston LJ, Shizurn JA, Stockerl-Goldstein KE, et al. Transplantation of highly purified CD34+Thy-1+ 
hematopoietic stem cells in patients with metastatic breast cancer. Biol Blood Marrow Transplant. 2000; 6:262-271. [PubMed: 10871151]

32. Vose JM, Bierman PJ, Lynch JC, Atkinson K, Juttner C, Hanania CE, Bociek G, Armitage JO. Transplantation of highly purified CD34+Thy-1+ hematopoietic stem cells in patients with recurrent indolent non-Hodgkin's lymphoma. Biol Blood Marrow Transplant. 2001; 7:680-687. [PubMed: 11787531]

33••. Taraldsrud E, Grogaard HK, Solheim S, Lunde K, Floisand Y, Arnesen H, Seljeflot I, Egeland T. Age and stress related phenotypical changes in bone marrow CD34+ cells. Scand J Clin Lab Invest. 2009; 69:79-84. This paper provides evidence of an increased frequency of human hematopoietic stem and progenitor cells in the bone marrow of elderly people. This study refutes the prevailing view suggesting that stem/progenitor cell frequency declines with age. [PubMed: 18836945]

34. Muller-Sieburg CE, Cho RH, Karlsson L, Huang JF, Sieburg HB. Myeloid-biased hematopoietic stem cells have extensive self-renewal capacity but generate diminished lymphoid progeny with impaired IL-7 responsiveness. Blood. 2004; 103:4111-4118. [PubMed: 14976059]

35. Dykstra B, Kent D, Bowie M, McCaffrey L, Hamilton M, Lyons K, Lee SJ, Brinkman R, Eaves C. Long-term propagation of distinct hematopoietic differentiation programs in vivo. Cell Stem Cell. 2007; 1:218-229. [PubMed: 18371352]

36••. Beerman I, Bhattacharya D, Zandi S, Sigvardsson M, Weissman IL, Bryder D, Rossi DJ. Functionally distinct hematopoietic stem cells modulate hematopoietic lineage potential during aging by a mechanism of clonal expansion. Proc Natl Acad Sci USA. 2010; 107:5465-5470. This paper demonstrates that lineage-biased HSC clones can be prospectively isolated based on expression levels of CD150 in additional to traditional HSC markers. It further shows that a subset HSC clones having myeloid-biased lineage potential expand to predominate the stem cell pool during aging. [PubMed: 20304793]

37••. Challen GA, Boles NC, Chambers SM, Goodell MA. Distinct hematopoietic stem cell subtypes are differentially regulated by TGF-beta1. Cell Stem Cell. 2010; 6:265-278. This paper demonstrates that lineage-biased HSC clones can be isolated based on differential Hoechst dye efflux activity. The authors present data suggesting that differential response to TGF-beta is a possible mechanism regulating HSC subtypes. [PubMed: 20207229]

38••. Morita Y, Ema H, Nakauchi H. Heterogeneity and hierarchy within the most primitive hematopoietic stem cell compartment. J Exp Med. 2010; 207:1173-1182. This paper shows the LSKCD34-compartment can be sub-fractionated using CD150 expression levels using single cell transplant experiments. The authors also discuss 'latent' HSCs with very low levels of primary transplant donor chimerism, that upon secondary transplant have a more robust reconstitution. [PubMed: 20421392]

39. Attema JL, Papathanasiou P, Forsberg EC, Xu J, Smale ST, Weissman IL. Epigenetic characterization of hematopoietic stem cell differentiation using miniChIP and bisulfite sequencing analysis. Proc Natl Acad Sci USA. 2007; 104:12371-12376. [PubMed: 17640913]

40. Maes J, Maleszewska M, Guillemin C, Pflumio F, Six E, Andre-Schmutz I, Cavazzana-Calvo M, Charron D, Francastel C, Goodhardt M. Lymphoid-affiliated genes are associated with active histone modifications in human hematopoietic stem cells. Blood. 2008; 112:2722-2729. [PubMed: 18625888]

41. Weishaupt H, Sigvardsson M, Attema JL. Epigenetic chromatin states uniquely define the developmental plasticity of murine hematopoietic stem cells. Blood. 2010; 115:247-256. [PubMed: 19887676]

42. Cui K, Zang C, Roh TY, Schones DE, Childs RW, Peng W, Zhao K. Chromatin signatures in multipotent human hematopoietic stem cells indicate the fate of bivalent genes during differentiation. Cell Stem Cell. 2009; 4:80-93. [PubMed: 19128795]

43. Kao JM, McMillan A, Greenberg PL. International MDS risk analysis workshop (IMRAW)/IPSS reanalyzed: impact of cytopenias on clinical outcomes in myelodysplastic syndromes. Am J Hematol. 2008; 83:765-770. [PubMed: 18645988]

44. Dhodapkar M, Grill J, Lust JA. Abnormal regional hypermethylation of the calcitonin gene in myelodysplastic syndromes. Leuk Res. 1995; 19:719-726. [PubMed: 7500648] 
45. Quesnel B, Guillerm G, Vereecque R, Wattel E, Preudhomme C, Bauters F, Vanrumbeke M, Fenaux P. Methylation of the p15(INK4b) gene in myelodysplastic syndromes is frequent and acquired during disease progression. Blood. 1998; 91:2985-2990. [PubMed: 9531610]

46. Tien HF, Tang JH, Tsay W, Liu MC, Lee FY, Wang CH, Chen YC, Shen MC.

Methylationofthep15(INK4B)geneinmyelodysplastic syndrome: it can be detected early at diagnosis or during disease progression and is highly associated with leukaemic transformation. $\mathrm{Br}$ J Haematol. 2001; 112:148-154. [PubMed: 11167795]

47. Jones PA, Taylor SM. Cellular differentiation, cytidine analogs and DNA methylation. Cell. 1980; 20:85-93. [PubMed: 6156004]

48. Silverman LR, Demakos EP, Peterson BL, Kornblith AB, Holland JC, Odchimar-Reissig R, Stone RM, Nelson D, Powell BL, DeCastro CM, et al. Randomized controlled trial of azacitidine in patients with the myelodysplastic syndrome: a study of the cancer and leukemia group B. J Clin Oncol. 2002; 20:2429-2440. [PubMed: 12011120]

49. Fukumoto JS, Greenberg PL. Management of patients with higher risk myelodysplastic syndromes. Crit Rev Oncol Hematol. 2005; 56:179-192. [PubMed: 15979321]

50. Daskalakis M, Nguyen TT, Nguyen C, Guldberg P, Kohler G, Wijermans P, Jones PA, Lubbert M. Demethylation of a hypermethylated P15/INK4B gene in patients with myelodysplastic syndrome by 5-Aza-2' -deoxycytidine (decitabine) treatment. Blood. 2002; 100:2957-2964. [PubMed: 12351408] 


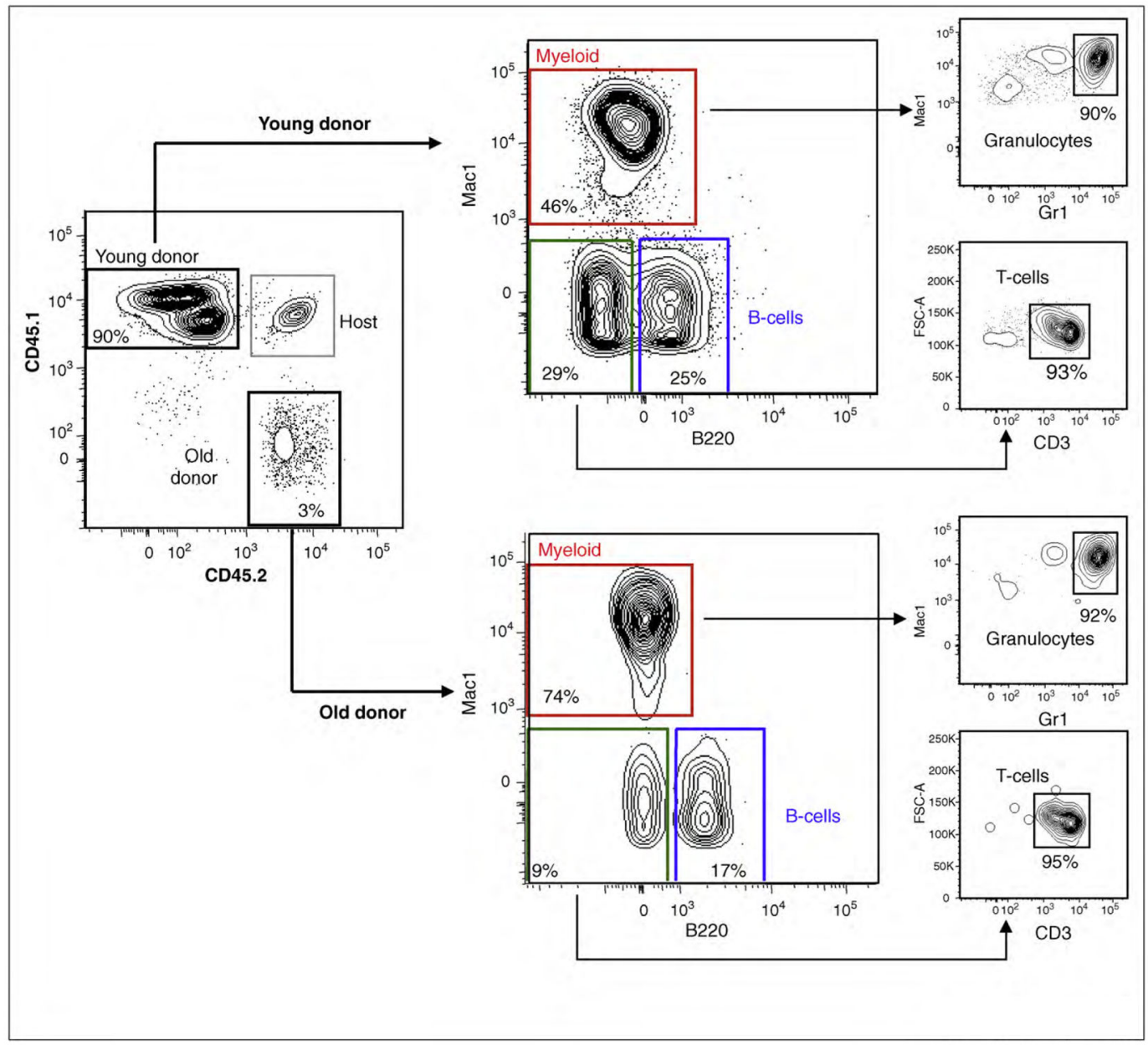

Figure 1.

In vivo reconstitution potential and lineage potential of young and old HSCs. $500 \mathrm{HSCs}$ $\left(\mathrm{LSKCD}^{-}{ }^{-} \mathrm{Flk2}^{-}\right.$) were isolated from 3 month-old CD45.1 or 24 month-old CD45.2 mice and injected in lethally irradiated CD45.1/CD45.2 (F1) mice along with a radioprotective dose of 300,000 F1 Sca-1-depleted bone marrow cells. Representative peripheral bleed data (17 weeks post-transplant) illustrate the point that HSCs from old mice exhibit a lower total reconstitution potential. Also, in the same microenvironment, HSCs from young donors yield lineage-balanced reconstitution, while a myeloid bias and reduced lymphoid reconstitution is observed from the stem cells of old donors. 


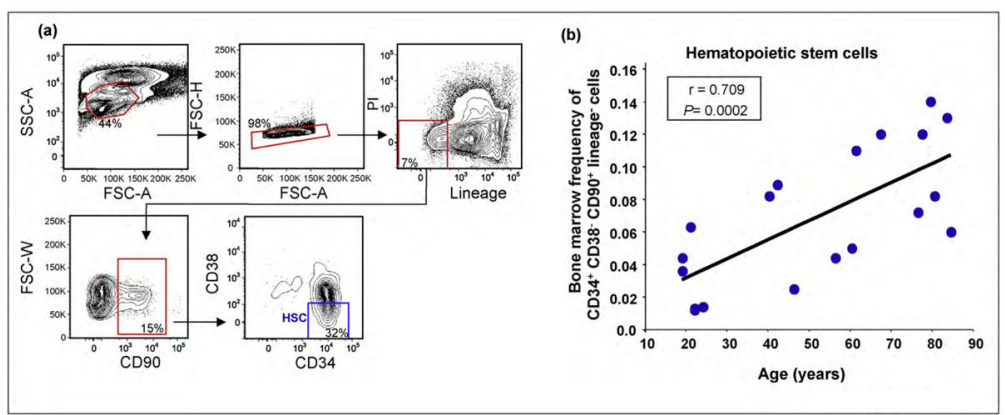

Figure 2.

Human hematopoietic stem cell frequency increases with age. (a) Identification of hematopoietic stem cells (Lineage ${ }^{-} \mathrm{CD} 90^{+} \mathrm{CD} 38^{-} \mathrm{CD} 34^{+}$) from a representative human bone marrow aspirate. Nineteen consented individuals ranging in age from 19 to 84 donated bone marrow aspirates for this study. Bone marrow mononuclear cells were first gated on size (FSC-A) and granularity (SSC-A), followed by doublet discrimination, lineage negativity (negative staining for a cocktail of antibodies against antigens found on differentiated blood cells including glycophorin A, CD11b, CD2, CD3, CD16, CD19, CD20, CD14, and CD56), and viability (propidium iodide (PI) negative). Finally, CD90 positive cells were gated for CD34 positivity and CD38 negativity. (b) Bone marrow frequency of HSCs (Lineage ${ }^{-} \mathrm{CD} 90^{+} \mathrm{CD} 38^{-} \mathrm{CD} 34^{+}$) bone marrow mononuclear cells plotted against donor age with Pearson correlation $(r)$ and $p$-value $(P)$ shown. Of note, analysis of bone marrow mononuclear cells indicate that a significant fraction of $\mathrm{CD} 34^{+}$cells stain positively for lineage markers and CD38 positive (not shown) stressing the importance of using a comprehensive marker panel when evaluating stem and progenitor cell populations. 


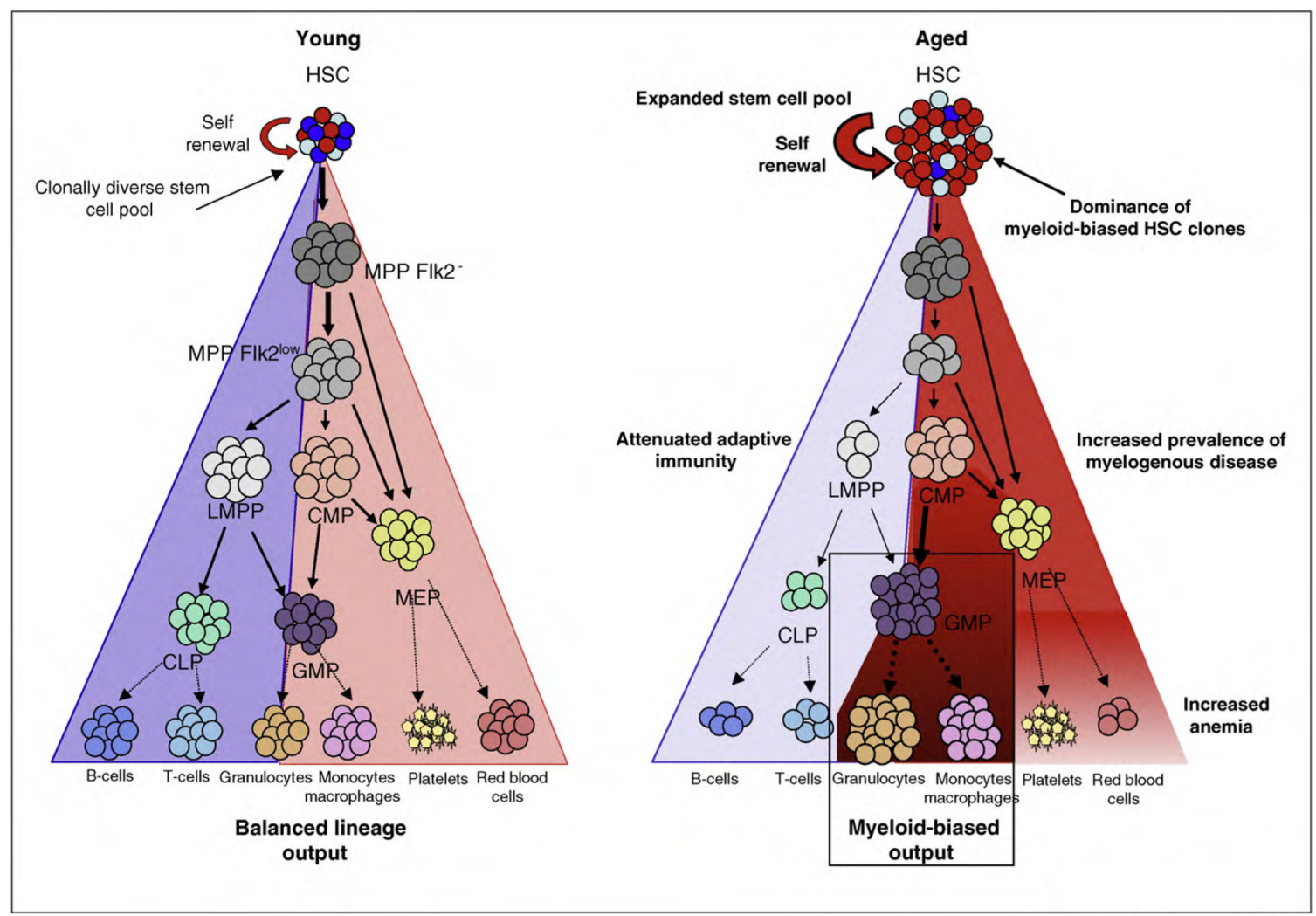

Figure 3.

Model of aging in the hematopoietic stem and progenitor cell compartment and impact on the aging hematopoietic system. Schematic representation of hematopoietic differentiation from hematopoietic stem cells (HSCs) through multipotent progenitors (MPPFlk2MPPFlk2 $2^{\text {low }}$ ) lymphoid-primed multi-potent progenitors (LMPP), common lymphoid progenitors (CLP), common myeloid progenitor progenitors (CMP), megakaryocyteerythrocyte progenitors (MEP), and granulocyte-monocyte progenitors (GMP), onto mature effector cells during aging, and proposed impact on the aged hematopoietic system. Steady state frequencies of stem and progenitor cells have been reported [11-13]. 